\title{
Study on the strength influence of pile driving disturbance on the surrounding soil
}

\author{
B. $\operatorname{Li}^{1234 *}$ \\ ${ }^{1}$ Tianjin Port Engineering Institute Ltd. of CCCC First Harbor Engineering Company Ltd., Tianjin, 30222 China; \\ ${ }^{2}$ Key laboratory of port geotechnical engineering, ministry of communications, PRC Tianjin, 30222 China; \\ ${ }^{3}$ Key laboratory of port geotechnical engineering of Tianjin, Tianjin, 30222 China; \\ ${ }^{4}$ CCCC First Harbor Engineering Company Ltd., Tianjin, 30222 China;
}

\begin{abstract}
The research on the strength influence of pile driving disturbance on the surrounding soil on marine environment is very less. This article is an actual pile driving project in the sea, the soil samplings with different distance from pile was taken and some laboratory test was done, the influence of soil property when pile driving is founded. According to the experimental results, the shear stress parameter and unconfined compressive strength index of soil in the hole increased with the increase of drilling depth, and the unconfined compressive strength index of soil in the hole nearly returned to the level of undisturbed soil 39 days after piling.
\end{abstract}

\section{Introduction}

In the process of dynamic pile sinking, especially when driving the long pile, the soil around the pile is disturbed by the continuous movement of the pile for a long time and the strength is weakened [1], that is, the lateral friction resistance of the pile with its continuous penetration will be substantially lower than the initial resistance. In ocean engineering, the strength weakening of soil around the pile is especially serious for the large diameter extra-long pile driving construction. In view of this problem, many scholars at home and abroad have carried out the corresponding research work. In 1955, Seed et al. [2] studied closed-mouth piles driven into silty clay, found that the bearing capacity of piles increased with time, and conducted comparative tests on soil samples taken from different positions of piles before and after driving, and found that the maximum soil strength loss on the side of piles could reach $70 \%$. Airhart et al. [3] conducted triaxial tests on soil samples taken before and after pile sinking and at different positions away from the pile circumference, and found that the strength of soil at the pile wall was greatly reduced when the pile sinking was completed, while the soil $0.75 \mathrm{~m}$ away from the pile wall had no significant change in the whole process of pile driving. Chinese researchers also conducted fruitful research and analysis on the soil around piles based on the aging problem of pile bearing capacity in engineering practice, and obtained some valuable results [4-5].

In this paper, based on the actual offshore pile driving project, soil around piles at different distances was sampled and laboratory tests were carried out to seek for the rule of influence of pile driving on soil properties, laying a foundation for subsequent research on influence mechanism of pile driving on soil properties around piles and stress distribution of soil around piles during pile driving.

\section{Project overview}

\subsection{Project introduction}

The project is mainly used for ocean tide monitoring, shellfish and other purposes. The construction of the floating cap covers an area of 100 square meter. The platform adopts a high pile cap structure with a base pile of $18 \mathrm{~mm}$ thick serving $1000 \mathrm{~mm}$. A total of 8 steel piles are arranged on the cap, with an inclination of 4:1 and a elevation of $-42 \mathrm{~m}$ at the bottom of the pile. The $600 \mathrm{kw}$ vibration hammer is hoisted by $200 \mathrm{t}$ crane, and the inclined pile construction is completed by pre-setting the guide frame on the positioning pile.

The platform of this project is $10 \mathrm{~m}$ long and $10 \mathrm{~m}$ wide, and the top elevation is $7.1 \mathrm{~m}$. The platform adopts a high pile bearing platform structure, with a $18 \mathrm{~mm}$ thick $1000 \mathrm{~mm}$ steel pipe pile serving as the base pile, with a $3.5 \mathrm{~m}$ long cruciform baffle pile embedded in the opening. Steel tube pile is made of pouring pile core concrete from the top of the pile to the mud surface. The upper part is the cast-in-place reinforced concrete pier, whose thickness is $1.5 \mathrm{~m}$. A total of 8 steel piles are arranged on the cap, with an inclination of $4: 1$ and a elevation of $42 \mathrm{~m}$ at the bottom of the pile. The $600 \mathrm{kw}$ vibration hammer is hoisted by a $200 \mathrm{t}$ crane. The construction of inclined pile is completed by pre-setting the installation guide frame on the positioning pile. After the positioning

*Corresponding author's e-mail: Lee_binbin@163.com 
and installation of the test pile, the vibration construction is completed and the piling is driven for about 1 hour.

\subsection{Engineering geology,}

According to the geotechnical investigation report, the foundation soil can be divided into the following 6 layers according to the genetic type and age characteristics, and further divided into 12 sublayers according to the mechanical properties.

1) Marine sediments of middle holocene formation

The thickness is $14.80 \mathrm{~m} \sim 14.90 \mathrm{~m}$, and the elevation of roof is $-2.97 \mathrm{~m} \sim-3.10 \mathrm{~m}$. This layer can be divided into four sublayers from top to bottom. The soil in this layer is evenly distributed in the horizontal direction.

2) Lower holocene marsh facies sediments

Thickness of $2.90 \mathrm{~m} \sim 3.00 \mathrm{~m}$, roof elevation of $17.79 \mathrm{~m} \sim-17.90 \mathrm{~m}$, mainly composed of silty clay, light gray, plastic state, no stratification, partial inclusion silty thin layer, is medium compressible soil. The soil in this layer is evenly distributed in the horizontal direction.

3) Continental alluvium of the lower holocene formation

Thickness of $3.20 \mathrm{~m} \sim 3.80 \mathrm{~m}$, roof elevation of $20.69 \mathrm{~m} \sim-20.90 \mathrm{~m}$, mainly composed of silty clay, grayyellow, plastic state, no stratification, including silty soil spot, is a medium compressible soil. The soil in this layer is evenly distributed in the horizontal direction.

4) Continental alluvium of the fifth formation of the upper pleistocene series

Thickness of $9.00 \mathrm{~m} \sim 9.50 \mathrm{~m}$, roof elevation of $24.10 \mathrm{~m} \sim-24.49 \mathrm{~m}$, mainly composed of silty clay, yellow-brown, plastic state, no stratification, containing rust, silty group, is a medium compressible soil. The soil in this layer is evenly distributed in the horizontal direction.

5) The fourth group of coastal tidal zone sediments of the upper pleistocene series

The thickness is $10.50 \mathrm{~m} \sim 11.20 \mathrm{~m}$, the elevation of roof is $-33.49 \mathrm{~m} \sim-33.97 \mathrm{~m}$, the soil in the horizontal direction of this layer is relatively uniform, stable distribution.

6) The third continental alluvium of the upper pleistocene series

This survey drill reached the lowest elevation of $60.69 \mathrm{~m}$, did not penetrate this layer, revealed the maximum thickness of $16.70 \mathrm{~m}$, roof elevation of $43.99 \mathrm{~m} \sim-44.80 \mathrm{~m}$, this layer can be divided into 2 sublayers from the top down. The soil in this layer is evenly distributed in the horizontal direction.

\section{Experimental research}

In order to understand the influence of vibrating hammer on the soil around the steel inclined pile and the restoration of the soil in the later period, the soil around the steel inclined pile was tested by in-situ soil sampling test before and after the steel inclined pile construction. The elevation table of test points is shown in table 1 .
Table 1 Table of elevation of test points

\begin{tabular}{|c|c|}
\hline Hole No. & elevation $(\mathrm{m})$ \\
\hline $\begin{array}{l}\text { S1(original soil taking hole } \\
\text { oblique hole) }\end{array}$ & -3.60 \\
\hline $\begin{array}{l}\text { S2(straight hole of original } \\
\text { soil taking hole) }\end{array}$ & -3.98 \\
\hline $\begin{array}{l}\text { S1 '(original soil taking hole } \\
\text { oblique hole) }\end{array}$ & -3.70 \\
\hline
\end{tabular}

Field test was carried out successively during July 1, 2015, solstice, July 24, 2015. The actual workload is shown in table 2 .

Table 2 Table of test work

\begin{tabular}{|c|c|c|c|}
\hline Hole class & $\begin{array}{c}\text { Hole } \\
\text { depth } \\
(\mathrm{m})\end{array}$ & total & Number \\
\hline $\begin{array}{c}\text { Original soil } \\
\text { hole oblique } \\
\text { hole }\end{array}$ & 43 & 2 & $\mathrm{~S} 1 、 \mathrm{~S} 1$ ' \\
\hline $\begin{array}{c}\text { Original soil } \\
\text { hole straight } \\
\text { hole }\end{array}$ & 41 & 1 & $\mathrm{~S} 2$ \\
\hline
\end{tabular}

\subsection{Field soil collection}

This test adopts the method of drilling, in-situ soil extraction and indoor geotechnical test, and adopts the drilling method of rotary mud retaining wall full core. The ultimate shear stress and unconfined compressive strength test of direct shear are analyzed. Put into the following equipment: $\mathrm{xy}-1$ type geological drilling machine, using rotary mud wall full core drilling. The soil taking hole was carried out in three stages: S1 hole 16 days after the southwest inclined pile driving, S2 hole 19 days after the pile driving, and S1 'hole 39 days after the pile driving. The laboratory test is a conventional physical and mechanical index and unconfined compressive strength test.

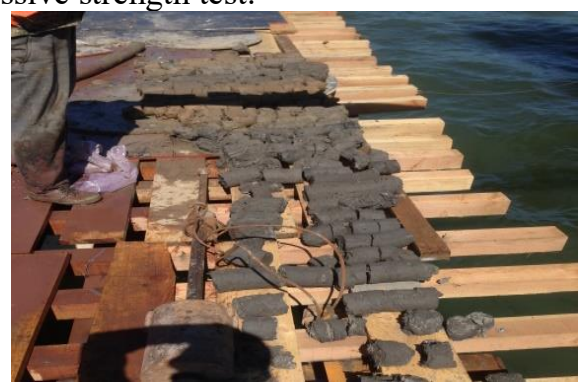

Figure 1. Sampling diagram of S1

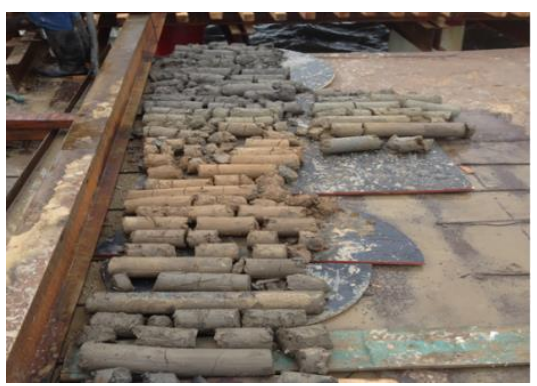

Figure 2. Sampling diagram of S1 
This test site was arranged according to the relevant requirements: 1 undisturbed soil sampling hole S2 (comparison hole), 2 undisturbed soil sampling holes S1 and S1 'hole were arranged in the test. After soil sampling, the experiment was carried out. The photos of on-site soil sampling were shown in figure 1.

\subsection{Test results}

According to the statistics of the limit shear stress parameters of direct shear quick shear, the limit shear stress parameters of soil in the hole gradually increase from the hole to the bottom of the hole and conform to the general law of soil. The soil in the hole is mainly composed of silty silty clay, silty clay and silty clay. According to the statistical parameters, it can be seen that the direct shear quick shear limit shear stress of soil in the hole is close to each other.

The relationship between soil elevation and unconfined compressive strength is shown in figure 3 .

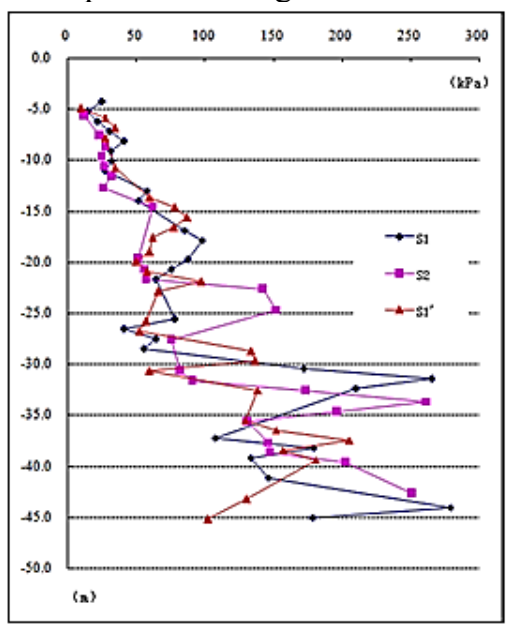

Figure 3. Relationship between soil sample depth and unconfined compressive strength

It can be seen from figure 3 that the unconfined compressive strength index of the soil in the holes increases with the increase of the soil sample depth, and the unconfined compressive strength index of the soil in the holes is similar. It can be seen from figure 3 that the unconfined compressive strength index of the soil in the hole within 39 days after piling is close to the level of S2 undisturbed soil.

\section{Conclusion}

The ultimate shear stress and unconfined compressive strength of the soil in the hole increase with the depth of the hole (soil sample). The soil in the hole is mainly divided into three categories: silty clay, silty clay and silty soil. According to the statistical parameters of the ultimate shear stress of the direct shear quick shear of the soil, it can be seen that the ultimate shear stress of the soil in the hole is close to each other. According to the unconfined compressive strength index of the soil, the unconfined compressive strength index of the soil in the hole within 39 days after piling is close to the level of the undisturbed soil $\mathrm{S} 2$.

\section{References}

1. LIANG Shou-xin. (1986) The basic method of the theory of stress wave applied in the pile foundation engineering. Proceedings of the Theory of Stress Wave Applied Pile Foundation Engineering. Lanzhou, 63-72.

2. SEED H B, REESE L C. (1955) The action of soft clay along friction piles. Proceedings of 4th International Conference on Soil Mechanics and Foundation Engineering. London, 842-867.

3. AIRHART T P, COYLE H M, HIRSCH T J, et al. (1969): Pile-soil system response in a cohesive soil. Performance of deep foundations, ASTM. New York. 264-294.

4. MABSOUT M E, REESE L C, TASSOULAS J L. (1995) Study of pile driving by finite-element method. Journal of Geotechnical Engineering, 121(7): 535-543.

5. LIYue-jian, CHEN Yun-min. (2001) Stress field and its effect on soil strength caused by pile installation in clay ground. Journal of the China Ralway Society, 23(4): 88-93. 